\title{
Synthesizing Colloidal Zinc Oxide Nanoparticles for Effective Disinfection; Impact on the Inhibitory Growth of Pseudomonas aeruginosa on the Surface of an Infectious Unit
}

\author{
Mahsa Omrani, Ebrahim Fataei* \\ Department of Environmental Sciences, Ardabil Branch, Islamic Azad University, \\ Ardabil, Iran
}

Received: 19 June 2017

Accepted: 19 September 2017

\begin{abstract}
Pseudomonas aeruginosa has innate characteristics of developing resistance. Therefore, it is obligatory to find the new antipseudomonal agents: Zno colloidal nanoparticles (NPs) synthesized via chemical deposition method. Then, TEM, SEM, DLS, and UV-visible were done. Sampling was achieved from not the same sections of infectious unit and then Pseudomonas aeruginosa was isolated from hospital and its antibiotic resistance pattern was determined. Disc diffusion, cavity, MIC, and MBC tests were done. Absorption of UV-visible occurred at about $350 \mathrm{~nm}$. The mid-range of hydrodynamic diameter and the average size of the $\mathrm{ZnO}$ NPs were 1.48 um and $5 \mathrm{~nm}$, respectively. Isolated Pseudomonas aeruginosa was resistant to Trimethoprim, Ampicillin, and Nitrofurantoin. The disc diffusion and cavity test of antibiotic-resistant Pseudomonas aeruginosa showed respectively the least sensitivity to $\mathrm{ZnO}$ (DIZ $=8 \mathrm{~mm}$ and $5 \mathrm{~mm}$ ) in comparison of standard strain of Pseudomonas aeruginosa (DIZ = $10 \mathrm{~mm}$ and $8 \mathrm{~mm}$ ). According to the results, ZnO NPs could kill all antibiotic-resistant bacteria at a ratio of 1:16 $(\mathrm{MBC}=7.5 \mathrm{ppm})$. However, it was able to eliminate the standard strain of Pseudomonas aeruginosa at a ratio of 1:64 $(\mathrm{MBC}=0.937 \mathrm{ppm})$. This study demonstrated that $\mathrm{ZnO}$ NPs have high potential for disinfection of infectious units of hospitals against nosocomial infection - especially by Pseudomonas aeruginosa.
\end{abstract}

Keywords: zinc oxide, nanoparticles, Pseudomonas aeruginosa, disinfection, infectious unit

\section{Introduction}

Nosocomial infections are a major problem that nursing and medical staffs and also patients face daily [1].

*e-mail: ebfataei@iauardabil.ac.ir, ebfataei@gmail.com
Pseudomonas is a rod-shaped, aerobic, Gram-negative bacterium belonging to the family Pseudomonadaceae [2]. Risk factors for the growth of infections caused by Pseudomonas include neutropenia, cystic fibrosis, severe burns, and foreign device installations [3-4]. Pseudomonas can be diffused in hospitals by nursing staff, medical equipment, sinks, disinfectants, and food. Pseudomonas 
infections are a serious and important problem in hospitals for two reasons. First, patients who are critically ill can die from pneumonia caused by Pseudomonas. Second, the elimination of Pseudomonas aeruginosa in patients with infections is very difficult because of its resistance to a variety of antibiotics [5]. Pseudomonas aeruginosa currently shows resistance to the following antibiotics: penicillin $G$; aminopenicillin, including those combined withbeta-lactamase inhibitors; first-andsecondgeneration cephalosporins; piperacillin; piperacillin and tazobactam; cefepime; ceftazidime; aminoglycosides; the quinolones; and the carbapenems; as well as colistin and fosfomycin [6]. The increasing resistance of Pseudomonas aeruginosa to numerous antibiotics, as a result of excessive antibiotic administration, is now leading to the accumulation of antibiotic resistance and cross-resistance between antibiotics and the appearance of multidrug-resistant (MDR) forms of Pseudomonas aeruginosa [7-8].

In recent decades, nanotechnology has opened a new chapter in human life. Zinc oxide $(\mathrm{ZnO})$ is listed as "generally recognized as safe" (GRAS) by the U.S. Food and Drug Administration. Nano-sized particles of $\mathrm{ZnO}$ have more obvious antimicrobial activities than large particles, since the small size and high surfaceto-volume ratio of NPs allow for better interaction with bacteria [9]. Researchers have suggested the use of nano-metal oxides, especially zinc oxide nanoparticles $(\mathrm{ZnO} \mathrm{NPs})$ as superior disinfectants and antimicrobial agents for nosocomial infections microorganisms [10]. In other words, they report on the toxicity of $\mathrm{ZnO}$ NPs to gram-negative and gram-positive bacterial systems, Escherichia coli, Staphylococcus aureus, and primary human immune cells. Those results show that $\mathrm{ZnO}$ NPs may potentially prove useful as antimicrobial agents at selective therapeutic dosing regimens [9]. Also, Jayesh assumed that a combination of metal oxide NPs may give rise to more complete bactericidal effects against mixed bacterial populations [11]. It is obvious that the bactericidal effect of metal NPs has been attributed to their small size, photo-catalytic activity, and high surface-to-volume ratio, which allows them to interact closely with microbial membranes and is not merely due to the release of metal ions in solution [12]. In this study, colloidal ZnO NPs were synthetized and antibacterial effects of $\mathrm{ZnO}$ NPs against antibiotic resistance Pseudomonas aeruginosa isolated from the infection unit of Rasoul-e-Akram Hospital was investigated.

\section{Experimental}

\author{
Materials and Methods
}

\section{Synthesis of Colloidal Zinc Oxide NPs}

Colloidal $\mathrm{ZnO}$ NPs were synthetized using chemical analysis. First, $0.2 \mathrm{M}$ of zinc acetate dehydrate $\left(\mathrm{C}_{4} \mathrm{H}_{6} \mathrm{O}_{4} \mathrm{Zn}\right.$, Merck, Germany) was added to $25 \mathrm{ml}$ of methanol $\left(\mathrm{CH}_{3} \mathrm{OH}\right.$, Merck, Germany). In addition, $1.2 \mathrm{M}$ of sodium hydroxide ( $\mathrm{NaOH}$, Merck, Germany) was added to $25 \mathrm{ml}$ of methanol. Then, the zinc acetate dehydrate solution was poured drop by drop to sodium hydroxide solution. The final solution was placed on a magnetic stirrer for about 3 hours. The solution was centrifuged for $10 \mathrm{~min}$ at 4,000 rpm. Next, nano-colloidal particles were dried at room temperature. The powder of ZnO NPs was added to $50 \mathrm{ml}$ of deionized distilled water and then sonicated.

\section{Characterization}

The characterization of $\mathrm{ZnO}$ NPs was confirmed with UV-visible (BioTek, microplate reader, U.S), dynamic light scattering (DLS) (A-ONE Enc., Korea), inductively coupled plasma mass spectrometry (ICPMS), scanning electron microscopy (SEM) (Hitachi, Japan), and Transmission Electron Microscopy (TEM) (Philips, Germany). In addition, dilutions of ZnO NPs were prepared according to Table 1 .

\section{Sampling}

This study was conducted in the infection unit of medium-sized Rasoul-e-Akram Hospital in the city of Tehran. Also, sampling was conducted for a month, from 22 September to 22 October 2016. The research considered contaminated surfaces that are routinely and collectively handled by professionals from this service. Randomly, sampling was done from different sections of the infectious unit, especially in burn patient rooms, such as workbenches, beds, doorknobs, and walls. Swabs were quickly sent to the antimicrobial resistance research center (ARRC) laboratory. Note that just one sample of isolated Pseudomonas aeruginosa was chosen for this research.

\section{Bacteriological Analysis}

All swabs were placed into the enrichment medium - BHI broth (Merck, Germany) for $24 \mathrm{~h}$ at $37^{\circ} \mathrm{C}$.

Table 1. The approximate concentration of ZnO NPs in different dilutions in a final volume of one ml.

\begin{tabular}{|c|c|c|c|c|c|c|c|c|c|}
\hline & \multicolumn{7}{|c|}{ Dilution } \\
\hline \multirow{2}{*}{$\mathrm{ZnO}$} & $1: 2$ & $1: 4$ & $1: 8$ & $1: 16$ & $1: 32$ & $1: 64$ & $1: 128$ & $1: 256$ & $1: 512$ \\
\cline { 2 - 9 } & $\sim 30 \mathrm{ppm}$ & $\sim 15 \mathrm{ppm}$ & $\sim 7.5 \mathrm{ppm}$ & $\sim 3.75 \mathrm{ppm}$ & $\sim 1.875 \mathrm{ppm}$ & $\sim 0.937 \mathrm{ppm}$ & $\sim 0.468 \mathrm{ppm}$ & $\sim 0.234 \mathrm{ppm}$ & $\sim 0.117 \mathrm{ppm}$ \\
\hline
\end{tabular}


Table 2. Lists of antibiotic discs used on isolated Pseudomonas aeruginosa.

\begin{tabular}{|c|c|c|}
\hline Antimicrobial agent & Symbol and count & Made in \\
\hline Cefazolin & CEF10 & PADTAN TEB Co. Iran \\
\hline Gentamycin & GM10 & PADTAN TEB Co. Iran \\
\hline Amikacin & An & PADTAN TEB Co. Iran \\
\hline Cefepime & FEP30 & PADTAN TEB Co. Iran \\
\hline Cefotaxime & CTX30 & PADTAN TEB Co. Iran \\
\hline Ciprofloxacin & CP10 & PADTAN TEB Co. Iran \\
\hline Trimethoprim sulfa methoxazole & TMP5 & PADTAN TEB Co. Iran \\
\hline Meropenem & MEN10 & PADTAN TEB Co. Iran \\
\hline Ceftazidime & CAZ30 & PADTAN TEB Co. Iran \\
\hline Nitrofurantoin & FM300 & PADTAN TEB Co. Iran \\
\hline Piperacillin Tazobactam & PTZ100/10 & PADTAN TEB Co. Iran \\
\hline Ampicillin & AM30 & MAST Co. UK \\
\hline Imipenem & IPM10 & MAST Co. UK \\
\hline Colistine & CL10 & PADTAN TEB Co. Iran \\
\hline Aztreonam & AZ15 & \\
\hline
\end{tabular}

The swabs were cultured on blood agar (Merck, Germany) and MacConkey Agar (Merck, Germany) for $24 \mathrm{~h}$ at $37^{\circ} \mathrm{C}$. After that, samples were tested for the presence of suspicious $\beta$-hemolytic colonies of Pseudomonas aeruginosa using gram staining and biochemical tests such as oxidase and catalase, oxidation and fermentation, methyl red, and Voges-Proskauer reactions. Indole, SH2, motility in SIM medium (Merck, Germany), pigmentation, lactose fermentation, sugar fermentation in TSI medium (Merck, Germany) were also analyzed and, finally, Pseudomonas aeruginosa was approved.

\section{Identifying and Determining Antibiotic Resistance Patterns of Pseudomonas aeruginosa}

Biochemical tests were used to confirm the identification of antibiotic resistance of Pseudomonas aeruginosa. We used the disk diffusion method (KirbyBauer) in accordance with the standard clinical and laboratory standards institute (CLSI) and the National Committee for Clinical Laboratory Standards (NCCLS) to determine antibiotic resistance patterns. Antibiotic discs for isolated Pseudomonas aeruginosa are listed in Table 2 [13].

\section{Disk Diffusion and Cavity Tests}

First, one $\mathrm{ml}$ of colloidal $\mathrm{ZnO}$ NPs (60 ppm) were poured into the sterile tubes, and after that blank discs were placed in the tube. Then it was sonicated at room temperature at a frequency of $28 \mathrm{KHz}$ (Fisher Scientific, U.S.) for $10 \mathrm{~min}$. Next, discs were placed in desiccators for one hour at room temperature. Subsequently, two or three colonies of freshly antibiotic resistance of isolated Pseudomonas aeruginosa and standard strain of Pseudomonas aeruginosa (ATCC 27853) were injected into a test tube containing $10 \mathrm{ml}$ of sterile normal saline (Mahban Darou. Iran) and equivalent to $0.5 \mathrm{McFarland}$. Then, $100 \mu \mathrm{l}$ of bacterial suspension was cultured on Muler Hinton agar (MHB) (Merck, Germany). A disc impregnated with $\mathrm{ZnO}$ NPs was polluted on $\mathrm{MHB}$ and incubated at $37^{\circ} \mathrm{C}$ for at least 18 hours. In order to perform a cavity test, we drilled several cavities on MHB and poured $100 \mu \mathrm{l}$ of $\mathrm{ZnO}$ NPs into them. All tests were replicated three times.

\section{MIC and MBC Tests}

The serial dilution method was used to determine the minimum inhibitory concentration (MIC) of the colloidal ZnO NPs $[12,14]$. We used 24 micro-plate wells for this test. In this way, 12 wells were filled with one $\mathrm{ml}$ of the liquid Muller Hinton broth (MHB) medium. Then, one $\mathrm{ml}$ of $\mathrm{ZnO}$ NPs was sonicated and added to No. 1 well. Subsequently, serial dilution was done. The $12^{\text {th }}$ well was continuously dedicated as a positive control. In total, microbial suspensions of isolated antibiotic resistance of Pseudomonas aeruginosa and standard strain of Pseudomonas aeruginosa (ATCC27853) containing $1.5 \times 10^{8}$ CFU.ml ${ }^{-1}$ were added to wells and incubated at $37^{\circ} \mathrm{C}$ for 24 hours. For measuring the minimum bactericidal concentration (MBC), a loopfull from each well was inoculated on Muller Hinton agar (MHA) medium and incubated at $37^{\circ} \mathrm{C}$ for 24 hours. The $\mathrm{ZnO}$ NP concentration illustrating bactericidal effect was picked out based on the absence of colonies 


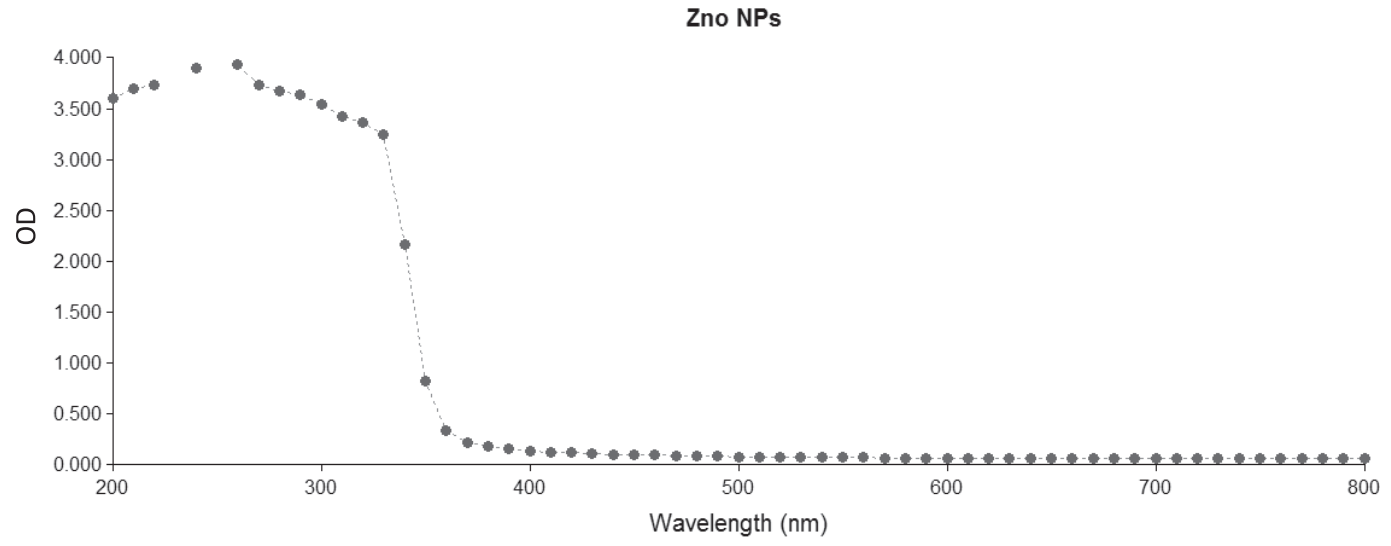

Fig. 1. UV-visible spectrum of zinc oxide nanoparticles

on the agar plate. All the experiments were replicated three times $[12,14]$.

\section{Results}

In the present study, the ZnO NPs were synthesized by chemical assay and planned for anti-bacterial activity against antibiotic resistance Pseudomonas aeruginosa isolated from a hospital infection unit. $\mathrm{ZnO} \mathrm{NPs}$ in aqueous solution were proven via UV-visible spectrum. Absorption of ZnO NPs was done between $200 \mathrm{~nm}$ and $800 \mathrm{~nm}$. Characteristic absorption of surface plasmon resonance band occurred at about $350 \mathrm{~nm}$ (Fig. 1) [15-16]. The size measured in DLS technique is bigger in comparison with macroscopic techniques. The midrange hydrodynamic diameter of the ZnO NPs was 1.48 um [16-17]. Also, according to a previous study the Zeta potential of $\mathrm{ZnO}$ NPs was calculated at about $3.13 \mathrm{mV}$. On the other hand, inductively coupled plasma mass spectrometry (ICP-MS) proceedings shows that the concentration of ZnO NPs was around 55 ppm [18-20]. Fig. 2 shows the SEM image of ZnO NPs. The distribution of particle size was done with a $100 \mathrm{~K}$ magnification on a

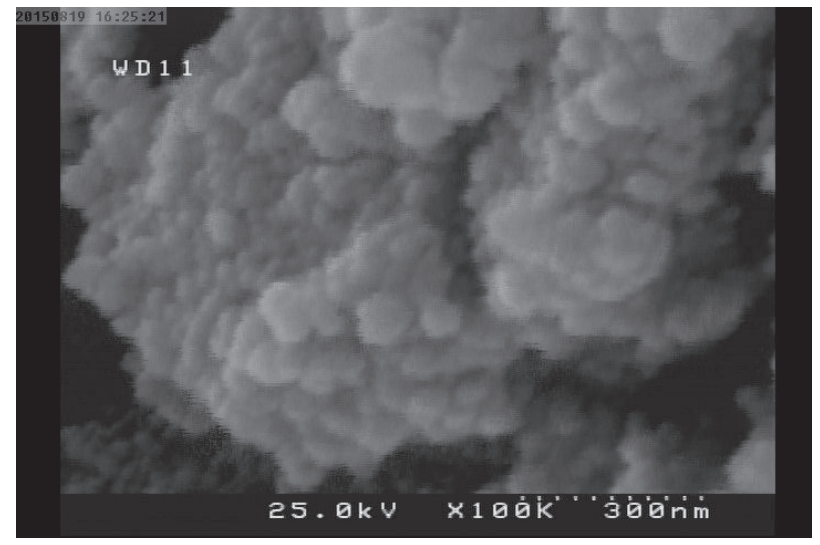

Fig. 2. SEM image of ZnO NPs $100 \mathrm{~K}$ magnification on a scale of $300 \mathrm{~nm}$ scale of $300 \mathrm{~nm}$. The TEM images of ZnO NPs are shown in Fig. 3. The NPs were spherical in shape with a smooth surface morphology, as well as agglomerates. The TEM image also shows that the produced $\mathrm{ZnO}$ NPs is more or less uniform in size and shape[19]. The average size of $\mathrm{ZnO}$ NPs was estimated with (Digimizer software, $\mathrm{v}$ 4.1.1.0) less than $5 \mathrm{~nm}$.

The biochemical tests of isolated Pseudomonas aeruginosa are presented in Table 3. Also, antibiotic resistance patterns of isolated Pseudomonas aeruginosa shows that it was sensitive to Gentamicin, Imipenem,

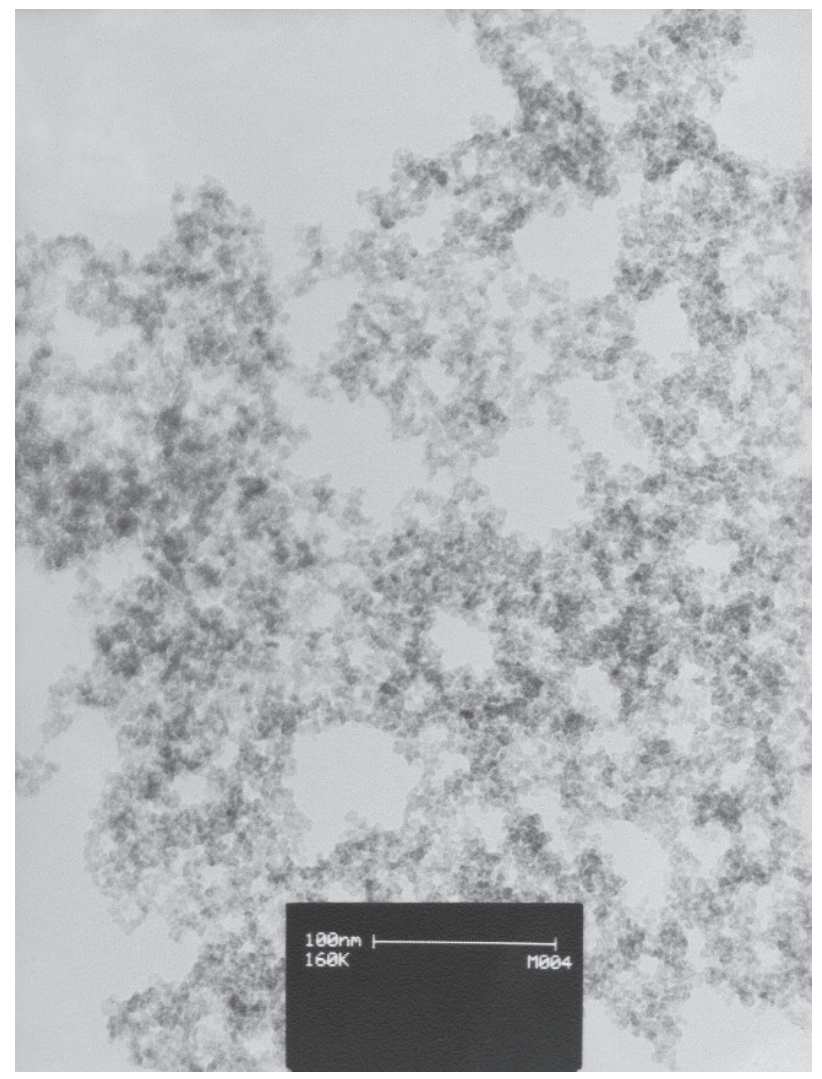

Fig. 3. TEM images of ZnO NPs $160 \mathrm{~K}$ magnification at a scale of $100 \mathrm{~nm}$ 
Table 3. Results of biochemical tests of Pseudomonas aeruginosa.

\begin{tabular}{|c|c|c|c|c|c|c|c|c|c|c|}
\hline $\begin{array}{c}\text { Gram } \\
\text { stain }\end{array}$ & Motile & Oxidase & Lactose & TSI & $\mathrm{SH}_{2}$ & Catalase & Citrate & $\begin{array}{c}\text { OF } \\
\text { Aerobic }\end{array}$ & $\begin{array}{c}\text { OF } \\
\text { Anaerobic }\end{array}$ & $\beta$-hemolysis \\
\hline Negative & Positive & Positive & Negative & ALK/ALK & Negative & Positive & Positive & Positive & Negative & Positive \\
\hline
\end{tabular}

Table 4. Determination of antibiotic resistance patterns of Pseudomonas aeruginosa.

\begin{tabular}{|c|c|c|}
\hline Antimicrobial Agent & Symbol and count & $\begin{array}{l}\text { Antibiotic } \\
\text { resistance }\end{array}$ \\
\hline Cefazolin & CEF & Resistance \\
\hline Gentamycin & GM10 & Sensitive \\
\hline Amikacin & An & Sensitive \\
\hline Cefepime & FEP30 & Sensitive \\
\hline Cefotaxime & CTX30 & Sensitive \\
\hline Ciprofloxacin & CP10 & Sensitive \\
\hline $\begin{array}{l}\text { Trimethoprim sulfa } \\
\text { methoxazole }\end{array}$ & TMP5 & Resistance \\
\hline Meropenem & MEN10 & Sensitive \\
\hline Ceftazidime & CAZ30 & Sensitive \\
\hline Nitrofurantoin & FM300 & Sensitive \\
\hline Piperacillin Tazobactam & PTZ100/10 & Sensitive \\
\hline Ampicillin & AM30 & Resistance \\
\hline Imipenem & IPM10 & Sensitive \\
\hline Colistine & CL10 & Sensitive \\
\hline Aztreonam & $\mathrm{AZ}$ & Sensitive \\
\hline Ceftriaxone & CRO30 & Sensitive \\
\hline Cefixime & CFM5 & Sensitive \\
\hline Nitrofurantoin & FM300 & Sensitive \\
\hline
\end{tabular}

Colistin, Ciprofloxacin, Meropenem, Amikacin, Ceftazidime, Cefepime, and Cefotaxime. Likewise, it was resistant to Trimethoprim, Ampicillin, and Nitrofurantoin (Table 4). Disc diffusion and cavity tests show that $\mathrm{ZnO}$ NPs have an antibacterial effect against the standard strain of Pseudomonas aeruginosa and isolated Pseudomonas aeruginosa from the infectious unit. According to the results, $\mathrm{ZnO}$ NPs could kill all antibiotic-resistant bacteria at a ratio of 1:16 $(\mathrm{MBC}=\sim 7.5 \mathrm{ppm})$. However, it was able to eliminate the standard strain of Pseudomonas aeruginosa at a ratio of 1:64 (MBC $=\sim 0.937$ ppm; Table 5). Consequently, however, colloidal nanoparticles could inhibit growth of Pseudomonas aeruginosa resistance and standard strain of Pseudomonas aeruginosa at ratios of 1:16 $(\mathrm{MIC}=\sim 3.75 \mathrm{ppm})$ and 1:128 $(\mathrm{MIC}=\sim 0.468 \mathrm{ppm})$, respectively. As observed, the standard strain of Pseudomonas aeruginosa shows the highest sensitivity to colloidal ZnO NPs (Table 5).

\section{Discussion}

One of the interesting characteristics of metal oxide NPs is their optical properties, which vary according to size and shape. Optical characteristics will vary with the size, shape, and spacing from each other and the refractive index of the surrounding NPs [21]. In this study, DLS presented the size and dispersion of $\mathrm{ZnO}$ NPs. The size measured in DLS technique is the hydrodynamic diameter of the theoretical sphere that diffuses with the same speed as the measured NPs. This size not only depends on the metallic core of the NPs, but it is also prejudiced with all substances adsorbed on the surface of the NPs and the thickness of the electrical double layer, moving along with the particle. Recently, Jafari and collegues synthesized colloidal Zno NPs using chemical analysis and measured its DLS, ICP-MS, SEM, and TEM images and UV-visible spectrum [22]. The characterizations of $\mathrm{ZnO}$ NPs were confirmed in accordance with a previous study [22]. TEM images of $\mathrm{ZnO}$ NPs showed that synthesis of NPs using chemical analysis could be present in very small sized NPs. Also, SEM images of $\mathrm{ZnO}$ NPs demonstrated agglomeration of particles in aquatic solution, just like the investigation of Jafari et al. [22].

Up to now, few reports have been obtainable on the anti-bacterial activity of $\mathrm{ZnO}$ metal oxide nanoparticles against antibioticresistant Pseudomonas aeruginosa [23-26]. According to Vijaya Chaudhari's research on antibiotic resistance patterns of Pseudomonas aeruginosa in a tertiary care hospital, the highest resistance depended on ciprofloxacin while the lowest was Meropenem [27]. In 2004 Gan and his colleagues showed that metal oxide NPs were capable of inhibiting or destroying many pathogenic bacteria [28]. Also, Guogang and

Table 5. Disk diffusion, Cavity, MIC, and MBC tests of ZnO NPs against Pseudomonas aeruginosa.

\begin{tabular}{|c|c|c|c|c|}
\hline & Disc Diffusion & Cavity & MIC & MBC \\
\hline Pseudomonas aeruginosa (ATCC 27853$)$ & $10 \mathrm{~mm}$ & $8 \mathrm{~mm}$ & $1: 128(\sim 0.468 \mathrm{ppm})$ & $1: 64(\sim 0.937 \mathrm{ppm})$ \\
\hline Pseudomonas aeruginosa (Resistance) & $8 \mathrm{~mm}$ & $5 \mathrm{~mm}$ & $1: 16(\sim 3.75 \mathrm{ppm})$ & $1: 8(\sim 7.5 \mathrm{ppm})$ \\
\hline
\end{tabular}


Jayesh believed that dispersed suspension of metal oxide NPs with ultrasonic waves will increase antibacterial properties [29-30]. Currently, Dortet et al. found that "carba-NP test-II" was settled to identify carbapenemase production in Enterobacteriaceae and Pseudomonas spp., and to differentiate between the diverse types of carbapenemases. This is based on detection of the acidification resulting from imipenem hydrolysis, coupled with tazobactam and EDTA as inhibitors. In fact, it is a sensitivity and specificity technique for detecting not only carbapenemase activity but also carbapenemase types in Enterobacteriaceae and Pseudomonas aeruginosa [31]. Reddy in 2007 reported that ZnO NPs are not toxic against eukaryotic cells [9]. Also, Ling Yang confirmed that photo catalytic nanoparticles such as ZnO NPs increases its oxidation and reduction abilities while suppressing bacterial growth [32].

In 2016 Jafari studied the MIC and MBC of $\mathrm{ZnO}$ NPs against clinical antibiotic resistance Pseudomonas aeruginosa. Results showed that $\mathrm{ZnO}$ NPs were able to inhibit Pseudomonas aeruginosa at $512 \mu \mathrm{g} \cdot \mathrm{ml}^{-1}$, whereas MBC was $\geq 8,192 \mu \mathrm{g} \cdot \mathrm{ml}^{-1}[10]$. Also, they found that the lowest MIC in Pseudomonas aeruginosa was observed AgZnO NPs with $256 \mu \mathrm{g} \cdot \mathrm{ml}^{-1}$, which has the highest inhibitory effect on Pseudomonas aeruginosa. In fact, the greatest resistance to zinc oxide NPs was seen in Pseudomonas aeruginosa.

Although the antibacterial mechanism of $\mathrm{ZnO}$ NPs is still unknown, the possibilities of membrane damage caused by direct or electrostatic interaction between $\mathrm{ZnO}$ and cell surfaces, cellular internalization of $\mathrm{ZnO} \mathrm{NPs}$, and the production of active oxygen species such as $\mathrm{H}_{2} \mathrm{O}_{2}$ in cells due to metal oxides have been suggested [33-34]. A few studies have suggested that the primary cause of the antibacterial function might be from the disruption of cell membrane activity [35]. However, Jafari confirmed that gram-negative antibiotic-resistant bacteria such as Klebsiella pneumoniae, Pseudomonas aeruginosa, and Escherichia coli have low sensitivity to colloidal $\mathrm{ZnO}$ NPs in comparison of gram-positive ones [10]. As mentioned before, another possibility is the induction of intercellular reactive oxygen species, including hydrogen peroxide, a strong oxidizing agent harmful to bacterial cells [36-37]. It has also been informed that ZnO NPs can be activated by UV and visible light to generate highly reactive oxygen species such as $\mathrm{OH}^{-}, \mathrm{H}_{2} \mathrm{O}_{2}$, and $\mathrm{O}_{2}^{-2}$. The negatively charged hydroxyl radicals and super-oxides cannot penetrate the cell membrane and are likely to remain on the cell surface, whereas $\mathrm{H}_{2} \mathrm{O}_{2}$ can penetrate bacterial cells [26].

\section{Conclusions}

Zinc oxide nanoparticles could be used as a high potential agent for disinfection of infectious units of hospitals against nosocomial infection - especially with Pseudomonas aeruginosa. The bottom line is that photocatalyst metal oxide nanoparticles' instance of zinc oxide colloidal nanoparticles not only can be self-cleaning disinfection, but also be able to control contamination in hospitals.

\section{Acknowledgements}

We are indebted to the research vice chancellor of Islamic Azad University of Ardabil for supporting this research. Also, we gratefully acknowledge the synthesis of nanoparticles by Iran University of Medicine Sciences. The authors would like to acknowledge the Central Laboratory of the University of Tehran for DLS analysis, and we gratefully acknowledge the executive director of the Iran-Nanotechnology Organization (government of Iran).

\section{References}

1. NADAF N., KANASE S. Antibacterial activity of Silver Nanoparticles singly and in combination with third generation antibiotics against bacteria causing hospital acquired infections biosynthesized by isolated Bacillus marisflavi YCIS MN 5. Dig J Nanomaterial Biostructure, 10 (4), 1189, 2015.

2. DE BENTZMANN S., PLÉSIAT P. The Pseudomonas aeruginosa opportunistic pathogen and human infections. Environmental microbiology, 13 (7), 1655, 2011.

3. HARDALO C., EDBERG S.C. Pseudomonas aeruginosa: assessment of risk from drinking water. Critical reviews in microbiology, 23 (1), 47, 1997.

4. MENA K.D., GERBA C.P. Risk assessment of Pseudomonas aeruginosa in water, in Reviews of Environmental Contamination and Toxicology 201, Springer. 71, 2009.

5. TRAN C.S., RANGEL S. M., ALMBLAD H., KIERBEL A., GIVSKOV M., TOLKER-NIELSEN T., HAUSER A.R., ENGEL J.N. The Pseudomonas aeruginosa type III translocon is required for biofilm formation at the epithelial barrier. PLoS Pathog, 10 (11), e1004479, 2014.

6. HANCOCK R.E., SPEERT D.P. Antibiotic resistance in Pseudomonas aeruginosa: mechanisms and impact on treatment. Drug resistance updates, 3 (4), 247, 2000.

7. ALOUSH V., NAVON-VENEZIA S., SEIGMAN-IGRA Y., CABILI S., CARMELI Multidrug-resistant Pseudomonas aeruginosa: risk factors and clinical impact. Antimicrobial agents and chemotherapy, 50 (1), 43, 2006.

8. YAYAN J., GHEBREMEDHIN B., RASCHE K. Antibiotic resistance of pseudomonas aeruginosa in pneumonia at a single university hospital center in germany over a 10 -year period. Plos one, 10 (10), e0139836, 2015.

9. REDDY K.M., FERIS K., BELL J., WINGETT D.G., HANLEY C., PUNNOOSE A. Selective toxicity of zinc oxide nanoparticles to prokaryotic and eukaryotic systems. Applied physics letters, 90 (21), 213902, 2007.

10. JAFARI A., MAJIDPOUR A., SAFARKAR R., MIRNUROLLAHI S.M., ARASTOO The Synthesis and Characterizes of Nano-Metallic Particles Against Antibiotic Resistant Bacteria, Isolated from Rasoule-Akram Hospital's Patients, Tehran, Iran. Journal of Molecular Biology Research, 6 (1), 80, 2016.

11. GHOSH T., BANDHU DAS A., JENA B., PRADHAN $\mathrm{CH}$. Antimicrobial effect of silver zinc oxide $(\mathrm{Ag}-\mathrm{ZnO})$ 
nanocomposite particles. Frontiers in Life Science, 8 (1), 47, 2015.

12. JAFARI A., GHANE M., SARABI M., SIYAVOSHIFAR F. Synthesis and antibacterial properties of zinc oxide combined with copper oxide nanocrystals. Oriental Journal of Chemistry, 27 (3), 811, 2011

13. DUDLEY M.N., PAUL G.A., SUJATA M.B., WILLIAM A.C., FERRARO M.J., JONES R.N. Background and rationale for revised Clinical and Laboratory Standards Institute interpretive criteria (breakpoints) for Enterobacteriaceae and Pseudomonas aeruginosa: I. Cephalosporins and aztreonam. Clinical infectious diseases, 56 (9), 1301, 2013.

14. DABBAGH M.A., MOGHIMIPOUR E., AMERI A., SAYFODDIN N. Physicochemical characterization and antimicrobial activity of nanosilver containing hydrogels. Iranian Journal of Pharmaceutical Research, 21, 2010.

15. MEULENKAMP E.A., Synthesis and growth of $\mathrm{ZnO}$ nanoparticles. The Journal of Physical Chemistry B, 102 (29), 5566, 1998.

16. TOMASZEWSKA E., SOLIWODA K., KADZIOLA K., TKACZ-SZCZESNA B., CELICHOWSKI G., CICHOMSKI M., SZMAJA W., GROBELNY Detection limits of DLS and UV-Vis spectroscopy in characterization of polydisperse nanoparticles colloids. Journal of Nanomaterials, 2013, 60, 2013.

17. ESMAEILI F., RAJABNEJHAD S., PARTOAZAR A.R., MEHR S.E., FARIDI-MAJIDI R., SAHEBGHARANI M., SYEDMORADI L., RAJABNEJHAD M.R., AMANI A. Anti-inflammatory effects of eugenol nanoemulsion as a topical delivery system. Pharmaceutical development and technology, 21 (7), 887, 2016.

18. MITRANO D.M., LESHER E.K., BEDNAR A., MONSERUD J., HIGGINS C.P., RANVILLE J.F. Detecting nanoparticulate silver using single-particle inductively coupled plasma-mass spectrometry,. Environmental Toxicology Chemistry, 31 (1), 115, 2012.

19. DEGUELDRE C., FAVARGER P.-Y., WOLD S. Gold colloid analysis by inductively coupled plasma-mass spectrometry in a single particle mode. Analytica Chimica Acta, 555 (2), 263, 2006.

20. GSCHWIND S., HAGENDORFER H., DANIEL A.F., GÜNTHER D. Mass quantification of nanoparticles by single droplet calibration using inductively coupled plasma mass spectrometry. Analytical chemistry, 85 (12), 5875, 2013.

21. YIN H., LANGFORD R., BURRELL R. Comparative evaluation of the antimicrobial activity of ACTICOAT antimicrobial barrier dressing. Journal of Burn Care \& Research, 20 (3), 195, 1999.

22. JAFARI A., KHARAZI SH., MOSAVARI N., MOVAHEDZADEH F., TEBYANIYAN M., JAFARI NODOOSHAN S., MAJIDPOUR A., MOSAVI T. Synthesis of Mixed Metal oxides Nano-Colloidal Particles and Investigation of the Cytotoxicity Effects on the Human Pulmonary cell lines: A prospective Approach in AntiTuberculosis Inhaled Nanoparticles. Orint. J. Chem, 33 (3), 2017.

23. NIGMATULLIN R.R., NIGMATULLIN R.R., OSOKIN S.I., BALEANU D., AL-AMRI S., AZAM A., MEMIC A.
The first observation of memory effects in the infrared (FTIR) measurements: do successive measurements remember each other? PloS one, 9 (4), e94305, 2014.

24. HAJIPOUR M.J., FROMM K.M., ASHKARRAN A.A., JIMENEZ DE ABERASTURI D., DE LARRAMENDI I.R., ROJO T.T., SERPOOSHAN V., PARAK W.J., MAHMOUDI M. Antibacterial properties of nanoparticles. Trends in biotechnology, 30 (10), 499, 2012.

25. LEE J.-H., KIM Y.-G., CHO M.H., LEE J. ZnO nanoparticles inhibit Pseudomonas aeruginosa biofilm formation and virulence factor production. Microbiological research, 169 (12), 888, 2014.

26. PADMAVATHY N., VIJAYARAGHAVAN R. Enhanced bioactivity of $\mathrm{ZnO}$ nanoparticles - an antimicrobial study. Science and Technology of Advanced Materials, 9 (3), 035004, 2008.

27. CHAUDHARI V., GUNJAL S., MEHTA M. Antibiotic resistance patterns of Pseudomonas aeruginosa in a tertiary care hospital in Central India. 2013.

28. GAN X., LIU T., ZHONG J., LIU X., LI G. Effect of silver nanoparticles on the electron transfer reactivity and the catalytic activity of myoglobin. ChemBioChem, 5 (12), 1686, 2004

29. REN G., REN G1, HU D., CHENG E.W., VARGASREUS M.A., REIP P., ALLAKER R.P. Characterisation of copper oxide nanoparticles for antimicrobial applications. International journal of antimicrobial agents, 33 (6), 587, 2009.

30. RUPARELIA J.P., CHATTERJEE A.K., DUTTAGUPTA S.P., MUKHERJI S. Strain specificity in antimicrobial activity of silver and copper nanoparticles. Acta biomaterialia, 4 (3), 707, 2008.

31. DORTET L., POIREL L., NORDMANN P. Rapid identification of carbapenemase types in Enterobacteriaceae and Pseudomonas spp. by using a biochemical test. Antimicrobial agents and chemotherapy, 56 (12), 6437, 2012.

32. YANG L., MAO J., Zhang X., XUE T., Hou T., Wang L., TU M. Preparation and characteristics of Ag/nano- $\mathrm{ZnO}$ composite antimicrobial agent. Nanoscience. 11 (1), 44, 2006.

33. FU G., VARY P.S., LIN C.-T. Anatase TiO2 nanocomposites for antimicrobial coatings. The Journal of Physical Chemistry B, 109 (18), 8889, 2005.

34. STOIMENOV P.K., ROSALYN L.K., GEORGE L.M., KENNETH J.K. Metal oxide nanoparticles as bactericidal agents. Langmuir, 18 (17), 6679, 2002.

35. BRAYNER R., FERRARI-ILIOU R., BRIVOIS N., DJEDIAT SH., BENEDETTI M.F., FIÉVET F. Toxicological impact studies based on Escherichia coli bacteria in ultrafine $\mathrm{ZnO}$ nanoparticles colloidal medium. Nano Letters, 6 (4), 866, 2006.

36. JONES N., RAY B., RANJIT K.T., MANNA A.C., Antibacterial activity of $\mathrm{ZnO}$ nanoparticle suspensions on a broad spectrum of microorganisms. FEMS microbiology letters, 279 (1), 71, 2008.

37. SAWAI J. Quantitative evaluation of antibacterial activities of metallic oxide powders $(\mathrm{ZnO}, \mathrm{MgO}$ and $\mathrm{CaO})$ by conductimetric assay. Journal of microbiological methods, 54 (2), 177, 2003. 
